Article

\title{
First-Principles Analysis of Vibrational Properties of Type II SiGe Alloy Clathrates
}

\author{
Dong Xue * and Charles W. Myles $\mathbb{D}$ \\ Department of Physics and Astronomy, Texas Tech University, Lubbock, TX 79409-1051, USA; \\ charley.myles@gmail.com \\ * Correspondence: dong.xue@ttu.edu; Tel.: +1-806-834-4563
}

Received: 17 April 2019; Accepted: 7 May 2019; Published: 10 May 2019

check for updates

\begin{abstract}
We have mostly performed vibrational studies of Type-II silicon-germanium clathrate alloys, namely, $\mathrm{Si}_{136-x} \mathrm{Ge}_{\mathrm{x}}(0<x \leq 128)$, using periodic density functional theory (DFT). Our computed lattice constant for various stoichiometric amount, namely, $x$, of Ge agrees to some extent with the observed X-ray diffraction (XRD) data, along with monotonically increasing dependence on $x$. According to our bandgap energy calculation via Vienna ab initio simulation package (VASP), $\mathrm{Si}_{128} \mathrm{Ge}_{8}$ has a "nearly-direct" bandgap of approximately $1.27 \mathrm{eV}$, which agrees well with the previously calculated result $(\sim 1.23 \mathrm{eV})$, which was obtained using the Cambridge sequential simulation total energy package (CASTEP). Most of our first-principles calculations focus on exploring the low-energy transverse acoustic (TA) phonons that contribute dominantly to the induction of negative thermal expansion (NTE) behavior. Moreover, our work has predicted that the $\mathrm{Si}_{104} \mathrm{Ge}_{32}$ framework exhibits NTE in the temperature range of 3-80 K, compared to the temperature regime (10-140 K) of NTE observed in such pure $\mathrm{Si}_{136}$. It is posited that the increased number of $\mathrm{Ge}-\mathrm{Ge}$ bonds may weaken the NTE effect substantially, as the composition, which is denoted as $x$, in $\mathrm{Si}_{136-\mathrm{x}} \mathrm{Ge}_{\mathrm{x}}$ is elevated from 32 (or 40) to 96 (or 104).
\end{abstract}

Keywords: alloy clathrate; mode Grüneisen parameter; negative thermal expansion; quasi-harmonic approximation

\section{Introduction}

In contrast to the diamond phase of silicon $(d-\mathrm{Si})$, there are two forms of crystalline clathrate: $\mathrm{Si}_{46}$ (Type I) and $\mathrm{Si}_{34}$ (Type II). Each of these pure materials consists of a covalently bonded framework that is composed of polyhedron cage elements. The enlarged unit cell of the Type II clathrate framework contains 136 atoms, exhibits a face-centered cubic (FCC) lattice structure and contains 20- and 28-atom cages that are connected periodically in a 4:2 ratio [1]. Growing interest in this expanded-volume silicon has arisen for two main reasons: the confirmed existence of superconductivity in metal-doped clathrate, namely, $\mathrm{Ba}_{x} \mathrm{Na}_{y} \mathrm{Si}_{46}$ [2-5], and the massive studies that have been conducted on efficient thermoelectric (TE) performance with guest-filled Si clathrates, which display glass-like thermal conductivity while behaving as a crystalline-cubic material [6-8]. Specifically, the efficiency of a TE device is manifested by the material's figure-of-merit, $Z T \equiv \sigma S^{2} T / \kappa$, where $\sigma$ denotes the electrical conductivity, $S$ is the Seebeck coefficient; $T$ is the absolute temperature, and $\kappa$ is the thermal conductivity. An effective way of enhancing ZT is through reducing the phonon thermal conductivity by nanostructuring [9], alloying [10], or introducing cage-like configuration that encapsulates rattling atoms, such as Si- or Ge-based clathrate compounds [11].

At present, many reports have discussed the electronic and thermodynamic properties of $\mathrm{Si}$ - and Ge-based Type II clathrate compounds [12-17] with the objectives of identifying prominent TE materials and gaining insight into interesting properties such as anomalous thermal expansion. One characteristic 
of the ideal TE candidate is minimal "glass-like" lattice thermal conductivity, which can originate from the scattering of acoustic phonons by the guest atoms $[18,19]$ while satisfying the "Phonon Glass Electron Crystal" (PGEC) paradigm, which was proposed by G. A. Slack [20,21]. Motivated by this concept, work on the Si-based Type II materials, namely, $\mathrm{Cs}_{8} \mathrm{Ga}_{8} \mathrm{Si}_{128}\left(\mathrm{Rb}_{8} \mathrm{Ga}_{8} \mathrm{Si}_{128}\right)$, and Ge-based Type I materials, namely, $\mathrm{Ba}_{8} \mathrm{Ga}_{16} \mathrm{Ge}_{30}\left(\mathrm{Ba}_{8} \mathrm{Ga}_{16} \mathrm{Si}_{5} \mathrm{Ge}_{25}\right)$, has been presented by $\mathrm{K}$. Biswas et al., in which the existence of the very low frequency rattling modes of guests, which contribute to the suppression of the phonon thermal conductivity, are demonstrated [22,23]. In addition, using density functional theory (DFT) within the local density approximation (LDA) approach, Tang et al. examined the thermal properties of the pure $\mathrm{Si}_{136}$ framework (which is sometimes denoted as $\mathrm{Si}_{34}$ ) and reported the negative thermal expansion (NTE) phenomenon in the temperature range of 10-140 K in experimental as well as theoretical manner [24]. More information about measured thermal properties of $\mathrm{Si}_{136}$ and bulk modulus with respect to $\mathrm{Na}_{x} \mathrm{Si}_{136}(0<x<24)$ (and low-Na Si clathrate-II compositions) are referred to articles $[25,26]$.

Recently, alloy clathrates have attracted wide research attention, and are a class of materials that possess a crystalline framework that is composed of more than one Group IV element (e.g., Si, $\mathrm{Ge}$ and $\mathrm{Sn}$ ). In this paper, the study of alloyed clathrates that are based on a mixture of Si and Ge is of great importance. Our calculational work is centered on these semiconducting clathrates, which have technological potential in both optical and electrical applications [27-29]. The SiGe binary clathrate compounds that contain metallic fillers in the endohedral sites of the polyhedron cage have been experimentally studied by Herrmann et al. [30]. In addition, Moriguchi et al. has investigated the energetics and electronic properties of the $\mathrm{Si}_{136-\mathrm{x}} \mathrm{Ge}_{\mathrm{x}}(0 \leq x \leq 136)$ system via first-principle codes [31]. Their work predicts direct and "nearly-direct" wide band gap whose value ranges from 1.2 to $1.3 \mathrm{eV}$ according to the Ge content $(x)$ which is in the range of 0 and 40 . We adopted their atomic compositions of $\mathrm{Si}_{136-\mathrm{x}} \mathrm{Ge}_{\mathrm{x}}$ to consider a full symmetry structure with equivalent Wyckoff sites, thereby facilitating the smooth initiation of our DFT calculations. Moreover, the physical origin of the low-temperature negative thermal expansion in $\mathrm{Si}_{136-\mathrm{x}} \mathrm{Ge}_{\mathrm{x}}(0 \leq x \leq 128)$ remains ambiguous and is under discussion [32-34]. To the best of our knowledge, one primitive model that has been applied to theoretically survey anharmonic thermodynamics that correspond to NTE behavior exploits the volume-dependent mode Grüneisen parameter $\left(\gamma_{\mathrm{i}}\right)$, which quantifies the deviation of the collective vibration of the lattice structure from simple harmonic oscillations. The measured shift of Raman lines under varied pressure also provides an experimental approach for examining the Grüneisen parameters when they are related to low-lying optical and acoustic modes of $\mathrm{Na}_{1} \mathrm{Si}_{136}$ [35].

In this work, we present an ab initio computational study on vibrational and thermal properties and their intrinsic relations to the finite- $T$ NTE phenomenon based on the optimized geometry of $\mathrm{Si}_{136-\mathrm{x}} \mathrm{Ge}_{\mathrm{x}}$ with respect to various stoichiometric compositions. The quasi-harmonic approximation (QHA) method is the most effective tool, which considers only the volume dependence of phonon anharmonicity and assumes that the temperature has a negligible effect on the phonon vibrational frequencies in the case of thermal expansion. Our calculated negative mode Grüneisen parameters, which are calculated according to $\gamma_{\mathrm{i}}=-U \operatorname{In} \omega_{\mathrm{i}} / U \operatorname{In} V$ and derived predominantly from heat-carrying transverse acoustic (TA) phonons that are located within the Brillouin zone (BZ), indirectly demonstrate the occurrence of NTE behavior. Here, vibrational mode frequency $\omega_{\mathrm{i}}$ depends on volume $V$ according to QHA. Furthermore, these first-principles results on $\gamma_{\mathrm{i}}$ remain to be comparable to the experimental Raman data $[35,36]$. The finite difference method (FDM) is utilized to estimate the above lattice dynamics quantities at $T=0$, which explains how volume dilation results in varied dynamical matrix elements of phonons that are subjected to different bands. For instance, contraction of our supercell model yields larger mode frequencies of the longitudinal acoustic (LA) phonon and transverse optic (TO) phonon, which are located at the BZ boundary (X or L point). In addition, we report a theoretical analysis of the electronic properties of $\mathrm{Si}_{136-\mathrm{x}} \mathrm{Ge}_{\mathrm{x}}$ clathrates. Our calculated lattice constant values, along with the band gap as a function of the Ge concentration which was normalized, correlate well with data that were recently obtained using an X-ray diffraction (XRD) instrument [37]. 


\section{Computational Approach}

Our first-principles calculations are conducted using the Vienna ab initio simulation package (VASP) [38], which exploits the Ceperley-Alder exchange-correlation potential and pseudopotentials that are obtained via the projector augmented wave (PAW) method. The energy cutoff parameter that accounts for the plane-wave basis was selected as the default value $(245.7 \mathrm{eV})$ when initiating the phonon calculations, which helps provide insight into the vibrational frequency of the $\Gamma$-point normal mode. A $4 \times 4 \times 4$ Monkhorst-Pack $k$-point grid [39] is selected for Brillouin zone integration.

The procedure of extracting electronic, vibrational and thermodynamic properties of the SiGe alloy clathrate from the periodic density functional theory computation is described as follows: The first step of geometry optimization is to relax the internal coordinates of the atoms, which are confined in a fixed unit cell of the materials. Then, the ground-state structural and electronic properties, such as the cohesive energy, were determined within the local density functional formalism. Next, a limited number of energy-volume $(E, V)$ pairs were fitted to a 3rd-order Birch-Murnaghan equation of state (EOS) [40], thereby enabling the calculation of the global minimum energy and the equilibrium lattice parameter. In addition to optimizing the geometry of each of the studied alloy clathrates, electronic properties, including the Fermi energy level $\left(E_{\mathrm{F}}\right)$, the electronic band structure (BS) and the electronic density of states (EDOS), are calculated in the framework of consistent structural settings.

To investigate the lattice dynamics of these Si-based clathrate compounds, a $2 \times 2 \times 2$ Monkhorst-Pack $k$-point was applied to obtain $\Gamma$-point vibration frequencies and dispersive relations, which are derived from the harmonic force constant matrix. In addition, the thermodynamic properties that are related to phonon anharmonicity were evaluated with the aid of the QHA method: The fractional change in volume, namely, $\Delta V / V$, which governs structural dilation or contraction, and the fractional change in the mode frequency are inspected to determine the microscopic Grüneisen parameter $\gamma_{\mathrm{i}}$. For this purpose, phonon calculations are repeated at three corresponding volume points that contain one equilibrium volume and two additional volumes that are slightly larger and smaller. Using the Feynman-Hellmann theorem, which is based on the FDM, the mode Grüneisen parameter of each phonon is evaluated by approximating the volume derivatives of dynamical matrix elements $\left(D_{i j}(\boldsymbol{q})\right)$ as $\Delta D_{i j}(q) / \Delta V$.

\section{Results and Discussion}

\subsection{Electronic Properties}

First, it is necessary to show the crystal structures with respect to $\mathrm{Si}_{136-\mathrm{x}} \mathrm{Ge}_{\mathrm{x}}(\mathrm{x}=8,40)$ in Figure 1. Here, the specified cubic unit cells are schematically given for the configurations that consist of 256 and 192 silicon atoms out of 272 atoms per cell respectively. The blue solid balls in the figure denote the Ge atoms that replace the Si counterparts at all $8 a$ Wyckoff sites in $\mathrm{Si}_{128} \mathrm{Ge}_{8}$ and at all $8 a$ along with $32 e$ Wyckoff sites in $\mathrm{Si}_{96} \mathrm{Ge}_{40}$. These clathrate alloys are expanded volume phase with sp ${ }^{3}$ tetrahedrally bonded framework. 


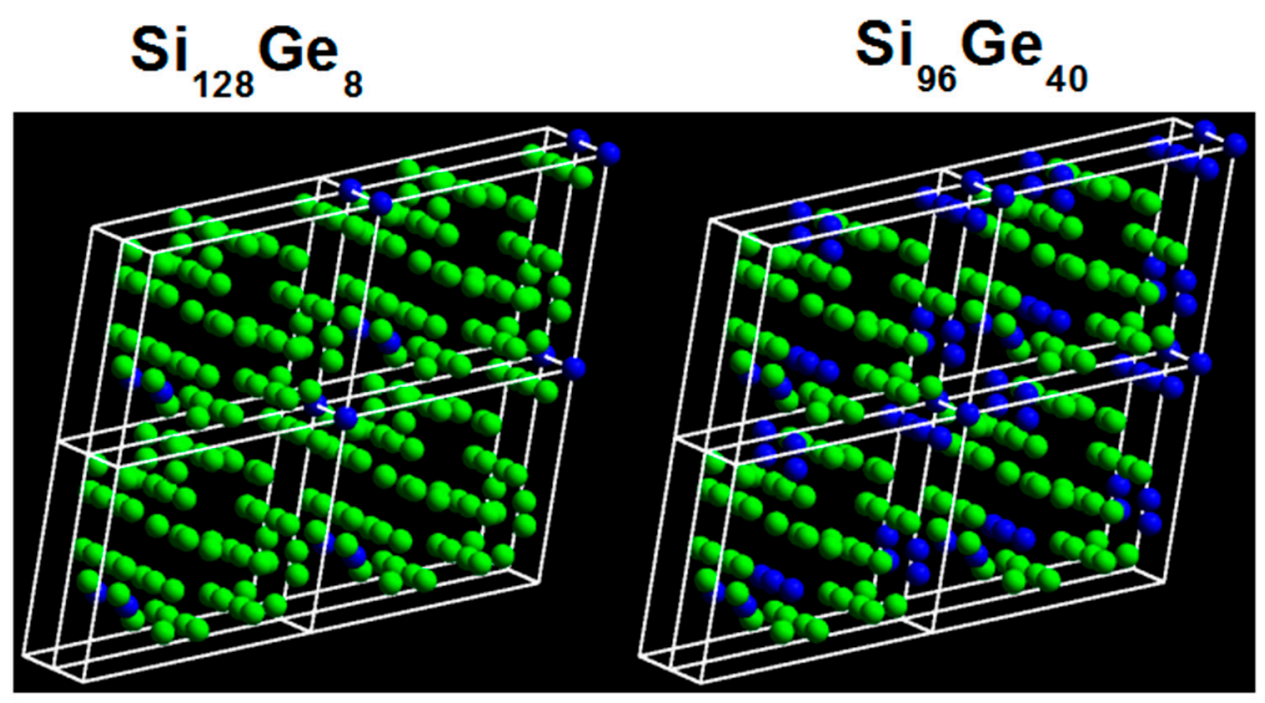

Figure 1. Cubic unit cells of $\mathrm{Si}_{136-\mathrm{x}} \mathrm{Ge}_{\mathrm{x}}(x=8,40)$ clathrate. The green solid balls represent the $\mathrm{Si}$ atoms while the blue solid ones denote the Ge atoms that act as substitutional framework hosts.

Next, we performed the ab initio computation to determine various electronic properties of Type II SiGe alloy clathrates, which are structurally formulated in covalently bonding configurations and exhibit sp ${ }^{3}$-hybridized configurations. Previously, in synthesis work on $\mathrm{Si}_{136-\mathrm{x}} \mathrm{Ge}_{\mathrm{x}}(0 \leq x \leq 136)$ by Baranowski et al., their phase formats were classified into two categories according to the $\mathrm{Ge}$ composition, which is denoted as $x$ [37]. Their study determined that the stoichiometric amount $(x)$ of Ge for amorphous formation ranges from approximately 20.4 to 68 . The amorphous region is likely caused by a miscibility gap. Analogous to those experimental results, the following figures present the results of our first-principles work on the composition-dependence of the lattice parameter and the bandgap for semiconducting $\left[\mathrm{Si}_{1-\mathrm{x}^{\prime}} \mathrm{Ge}_{x^{\prime}}\right]_{136}\left(0<x^{\prime}<1\right)$. Here, it is noticed that $x^{\prime}$ appearing in redefined chemical notation $\left[\mathrm{Si}_{1-x^{\prime}} \mathrm{Ge}_{\mathrm{x}^{\prime}}\right]_{136}$ remains equivalent to the ratio of Ge composition $(x)$ to 136 .

In Figure 2, the lattice parameter increases with the Ge content; a similar trend is observed between $X R D$ data and our LDA work in the absence of an amorphous region $\left(0.15 \leq x^{\prime} \leq 0.5\right)$. At various compositions of added Ge atoms (e.g., $x^{\prime}=0.15$ and $x^{\prime}=0.5$ ), the SiGe alloy clathrate exhibits a mostly crystalline phase with a small amount of amorphous background [37]. This demonstrates that the alloyed clathrate structures expand because of substitutional host atoms $(\mathrm{Ge})$, in comparison with the pure $\mathrm{Si}_{136}$ framework. In addition, for $x^{\prime} \sim 0.77$, our equilibrium lattice constant is $15.05 \AA$, which is approximately $0.3 \%$ smaller than the XRD value [37]. In analogy to this, the previously calculated lattice constant of $\mathrm{Si}_{136}(14.56 \AA)$ [1] is approximately $0.7 \%$ smaller than its experimental counterpart (14.63 ̊) [41]. 


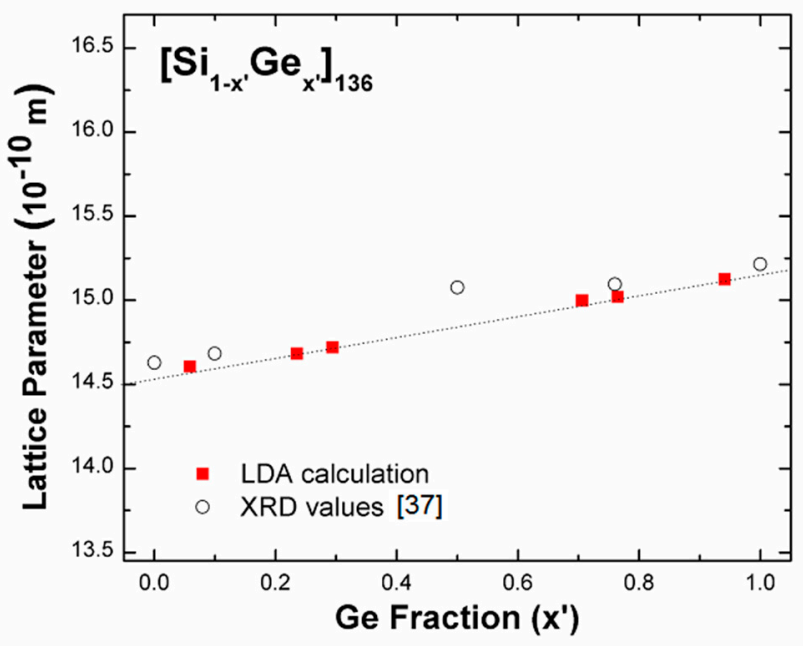

Figure 2. Local density approximation (LDA)-determined lattice parameter trend (red squares) as a function of the Ge mole fraction for $\left[\mathrm{Si}_{1-\mathrm{x}^{\prime}} \mathrm{Ge}_{\mathrm{x}^{\prime}}\right]_{136}$, in comparison with XRD data (open circles). The dashed line that is drawn for the LDA data was obtained via a linear fitting procedure and acts as a guide for the eye. The unit $10^{-10} \mathrm{~m}$ is equal to $1 \AA$.

A lower DFT-determined bandgap compared to the experiment result [37] in Figure 3 is expected no matter how $x^{\prime}$ appearing $\left[\mathrm{Si}_{1-x^{\prime}} \mathrm{Ge}_{\mathrm{x}^{\prime}}\right]_{136}$ changes, because the use of LDA formalism always causes the fundamental bandgap energy to be underestimated [42,43]. All optical band gap energies are measured from the top of the valence band at $\mathrm{L}$, the zero of which remains stably fixed and independent of the Ge concentration. Additionally, we theoretically found that degeneracy of the lowest conduction band at $\mathrm{L}$ and $\Gamma$ points is not noticeably distinguished in the presence of $\mathrm{Si}_{128} \mathrm{Ge}_{8}$ (see Figure 4), since eigenenergy of the conduction band edge at $\mathrm{L}$ is slightly higher (about only $30 \mathrm{meV}$ larger) than eigenenergy of the conduction band edge at $\Gamma$ point. Thus, we call this sort of bandgap a "nearly-direct" bandgap. Furthermore, the depicted band structure provided in Figure 4 shows that $\operatorname{Si}_{136-\mathrm{x}} \mathrm{Ge}_{\mathrm{x}}(x=8)$ exhibits the "nearly-direct" behavior regarding band gap redefinition. The calculated magnitude of such band gap value turns out to be approximately $1.27 \mathrm{eV}$ for $\mathrm{Si}_{128} \mathrm{Ge}_{8}$, which agrees well with the previous DFT result $(\sim 1.23 \mathrm{eV})$, which was obtained via the Cambridge sequential simulation total energy package (CASTEP) code [31]. 




Figure 3. Comparison of the predicted band gap (red squares) and the experimentally measured results (open circles) for $\left[\mathrm{Si}_{1-\mathrm{x}^{\prime}} \mathrm{Ge}_{\mathrm{x}^{\prime}}\right]_{136}\left(0<x^{\prime}<136\right)$. The dashed line acts as a guide for the eye.

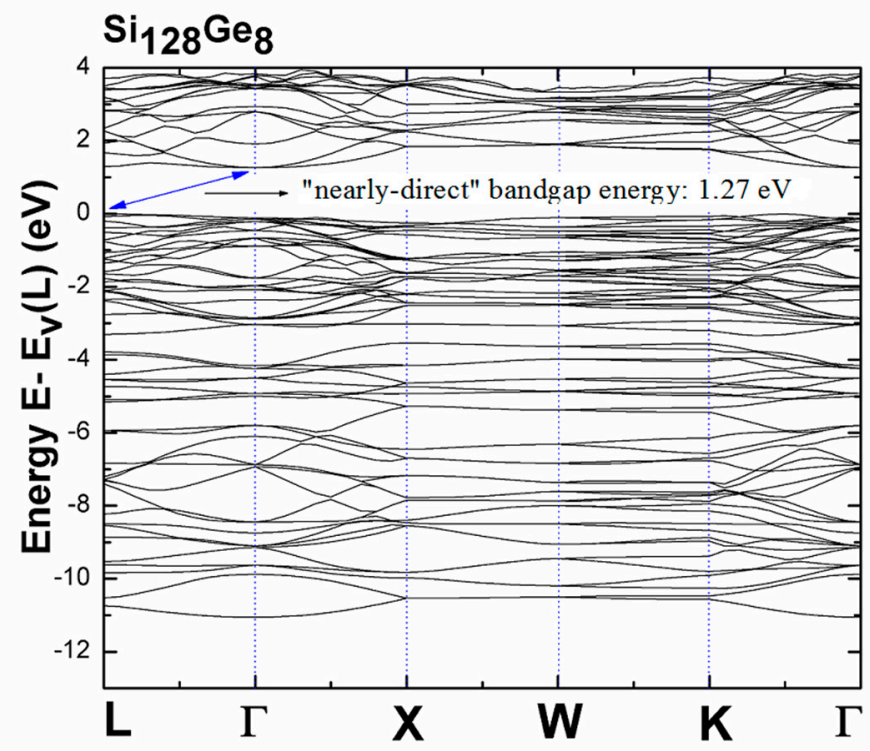

Figure 4. LDA-determined electronic band structures of $\mathrm{Si}_{128} \mathrm{Ge}_{8}$, where the zero of energy is set to be the valence band maximum at the $\mathrm{L}$ point $\left(\mathrm{E}_{\mathrm{V}}(\mathrm{L})\right)$. The "nearly-direct" bandgap is identified by blue arrow showing $1.27 \mathrm{eV}$.

In order to identify the detailed picture of "nearly-direct" band gap from the viewpoint of band structure (BS) given in Figure 4, we restrict the vertical scale about energy to range from $-1.5 \mathrm{eV}$ to $3.5 \mathrm{eV}$ for the purpose of zooming into the BS in an intricate manner. Therefore, Figure 5 shows the apparent "nearly-direct" behavior of bandgap energy, because eigenenergy of conduction band edge at $\mathrm{L}$ is only about $30 \mathrm{meV}$ larger than that of the conduction band edge at $\Gamma$ point, compared to significantly large band gap value (about $1.27 \mathrm{eV}$ ). 


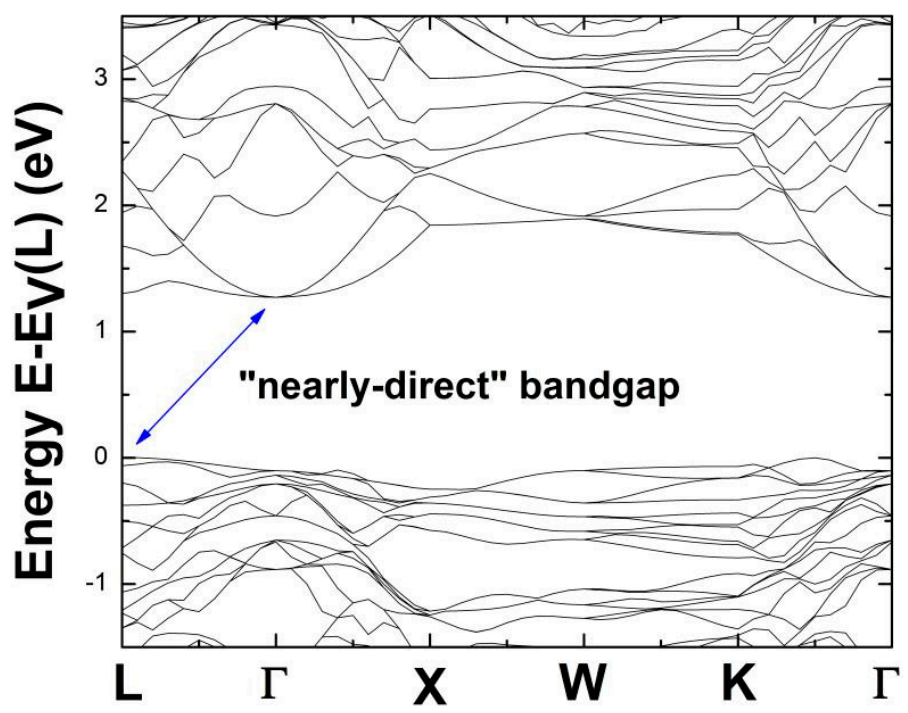

Figure 5. Detailed "nearly-direct" bandgap behavior within the energy $\left(E-E_{\mathrm{V}}(\mathrm{L})\right)$ range between $-1.5 \mathrm{eV}$ and $3.5 \mathrm{eV}$.

\subsection{Vibrational Properties}

The low-lying acoustic and optic mode regions are of greater importance than other portions of the predicted phonon-dispersion curves in Figure 6. Six phonon branches are primarily discussed here for each studied $\mathrm{Si}_{136-\mathrm{x}} \mathrm{Ge}_{\mathrm{x}}$ material $(x=8,40,104)$ : the longitudinal acoustic, transverse acoustic (TA (1) \& TA (2)) with double degeneracy along the specified direction, longitudinal optical (LO) and transverse optical (TO (1) \& TO (2)) branches, which might coincide at various $q$-points. To see the difference of the low-frequency portions $\left(0-75 \mathrm{~cm}^{-1}\right)$ of the dispersion relations for $\mathrm{Si}_{128} \mathrm{Ge}_{8}$ and $\mathrm{Si}_{96} \mathrm{Ge}_{40}$, we listed the frequency at $\mathrm{L}, \mathrm{X}, \mathrm{W}$ and $\mathrm{K}$ high-symmetry point in the following Table 1 .

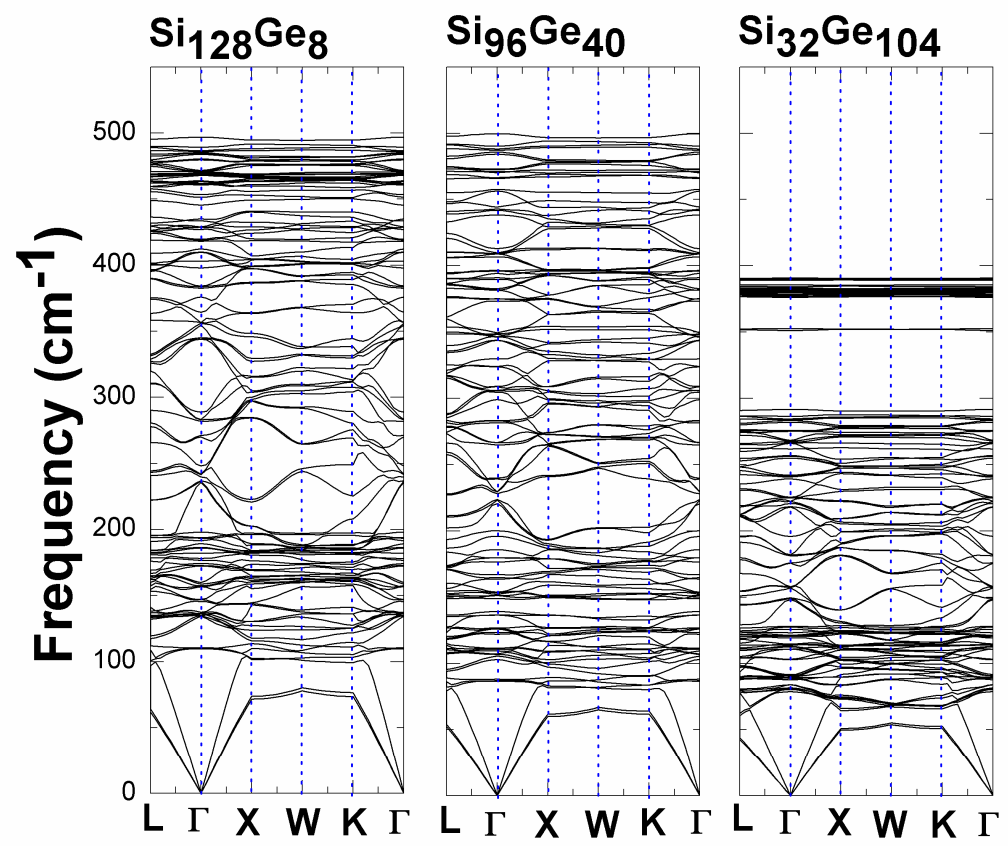

Figure 6. Dispersion relations of $\mathrm{Si}_{136-\mathrm{x}} \mathrm{Ge}_{\mathrm{x}}(x=8,40,104)$ that were obtained via VASP. 
Table 1. VASP-predicted vibrational mode frequency of lowest-lying acoustic phonon branch at $\mathrm{L}, \mathrm{X}, \mathrm{W}$, $\mathrm{K}$ high symmetry point for $\mathrm{Si}_{136-\mathrm{x}} \mathrm{Ge}_{\mathrm{X}}(x=8,40,104)$. Numerical values are given in the unit of $\mathrm{cm}^{-1}$.

\begin{tabular}{ccccc}
\hline Material & L & X & W & K \\
\hline $\mathrm{Si}_{128} \mathrm{Ge}_{8}$ & 61.89 & 71.81 & 77.93 & 73.72 \\
$\mathrm{Si}_{96} \mathrm{Ge}_{40}$ & 52.41 & 60.11 & 65.14 & 61.86 \\
$\mathrm{Si}_{32} \mathrm{Ge}_{104}$ & 42.74 & 49.84 & 53.90 & 50.84 \\
\hline
\end{tabular}

From the above Table, the vibrational frequency at fixed point decreases with the ascending order of Ge concentration $x$. Accordingly, the acoustic phonon speeds occur to be decreased with the increasing $x$.

Furthermore, the dispersion spectrum for $\mathrm{Si}_{32} \mathrm{Ge}_{104}$, which is displayed in Figure 6, shows its compressed optical band region $\left(71 \mathrm{~cm}^{-1} \sim 390 \mathrm{~cm}^{-1}\right)$, for which the maximum frequency is reduced by approximately $21 \%$ compared to $\mathrm{Si}_{128} \mathrm{Ge}_{8}$ and $\mathrm{Si}_{96} \mathrm{Ge}_{40}$. Near the top of the optical bands, an extremely flat and dense phonon mode region is observed for Ge-dominant alloy $\mathrm{Si}_{32} \mathrm{Ge}_{104}$. This apparent reduction of the highest optical band in $\mathrm{Si}_{32} \mathrm{Ge}_{104}$ might be attributable to the raising number of loose Ge-Ge bond which force constant was previously reported to be around $10 \mathrm{eV} / \AA^{2}$ according to Dong's work [44], compared to the "rigid" Si-Si bond, for which the effective force constant is approximately $24 \mathrm{eV} / \AA^{2}$ in $\mathrm{Si}_{136}$ [45]. Consequently, the existence of comparably weak coupling in the Ge-Ge bond might help suppress the sound speed of lattice phonons in $\mathrm{Si}_{136-\mathrm{x}} \mathrm{Ge}_{\mathrm{x}}$ when $x$ abruptly jumps from 8 to 104. In addition to that, a much smaller frequency range is used in Figure 7 to illustrate how the low-lying acoustic phonon branches differ from each other among the alloyed clathrate system $\mathrm{Si}_{136-\mathrm{x}} \mathrm{Ge}_{\mathrm{X}}(x=8,40,104)$. It is seen that each vibrational mode at specified point such as $\mathrm{L}, \mathrm{X}, \mathrm{W}$, $\mathrm{K}$ possesses the frequency value appearing in the Table 1. Simultaneously, the acoustic phonon speed is also reduced accordingly as $\mathrm{Si}_{128} \mathrm{Ge}_{8}$ is switched to be $\mathrm{Si}_{96} \mathrm{Ge}_{40}$ to $\mathrm{Si}_{32} \mathrm{Ge}_{104}$.

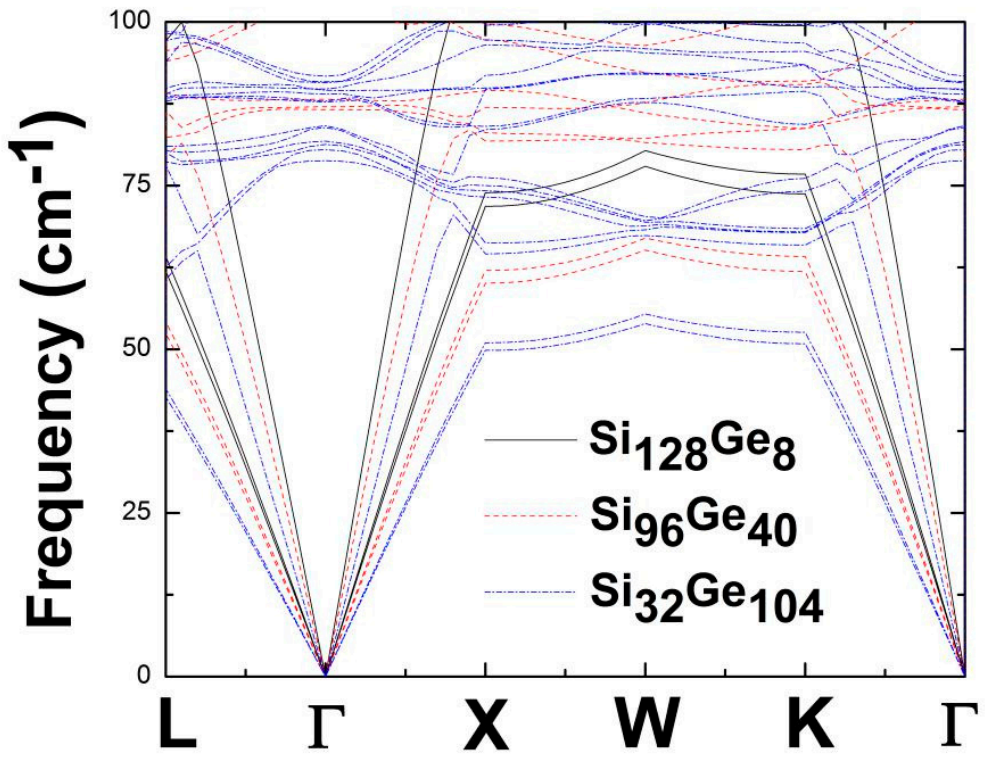

Figure 7. Low-frequency spectrum of $\mathrm{Si}_{128} \mathrm{Ge}_{8}$ (black solid line), $\mathrm{Si}_{96} \mathrm{Ge}_{40}$ (red dotted line), $\mathrm{Si}_{32} \mathrm{Ge}_{104}$ (blue dashed line).

We postulate that the collective motion of the framework atoms at each optimized geometry of $\mathrm{Si}_{136-\mathrm{x}} \mathrm{Ge}_{\mathrm{x}}$ is affected by the number of $\mathrm{Ge}-\mathrm{Ge}$ bonds, from both vibrational and transport points of view. The models that were considered here for the composition of the $\mathrm{Si}_{136-\mathrm{x}} \mathrm{Ge}_{\mathrm{x}}$ system were suggested by Moriguchi et al., who stated that host atoms reside at three inequivalent sites $(8 a, 32 e$, and $96 \mathrm{~g}$ ) [31]. On the basis of this ideal Fd3m symmetry, they noted that the number of Ge-Ge bonds in 
each framework unit cell ranges from 0 in $\mathrm{Si}_{128} \mathrm{Ge}_{8}$ (and $\mathrm{Si}_{104} \mathrm{Ge}_{32}$ ) to 8 in $\mathrm{Si}_{96} \mathrm{Ge}_{40}$ and 36 in $\mathrm{Si}_{40} \mathrm{Ge}_{96}$ (and $\mathrm{Si}_{32} \mathrm{Ge}_{104}$ ); hence, they follow an ascending order. As many more and more Ge-Ge bonds begin to replace $\mathrm{Si}-\mathrm{Si}$ bonds in $\mathrm{Si}_{136-\mathrm{x}} \mathrm{Ge}_{\mathrm{x}}$ framework with abruptly increasing stoichiometric amount of $\mathrm{Ge}$, the existence of the relatively weakened bond-bond strength (lowered force constant) of Ge-Ge is anticipated to relate to the lowered absolute value of negative mode Grüneisen parameter found in transverse acoustic phonons. This leads to that the weighted average of $\gamma_{\mathrm{i}}$ switches its sign from negative to positive at low-temperature regime (e.g. 24-100 K) corresponding to the weakened NTE effect, when $x$ is tuned from 8 (or 40) to 104. Detailed discussion on the derived mode Grüneisen parameter along with the macroscopic Grüneisen parameter is given in the following.

Additionally, one can notify the abrupt change in the dispersion bands from $\mathrm{Si}_{96} \mathrm{Ge}_{40}$ to $\mathrm{Si}_{32} \mathrm{Ge}_{104}$ clathrates of Figure 6. In order to zoom into the smaller phonon energy band widths to identify the "forbidden gap" as well as the thin band level located around $350 \mathrm{~cm}^{-1}$, we use Figure 8 to display the vibrational density of states along with the corresponding vibrational spectra confined inside the range of $295 \mathrm{~cm}^{-1}$ and $395 \mathrm{~cm}^{-1}$. Below the thin peak which is at around $350 \mathrm{~cm}^{-1}$, there exists the forbidden gap in the frequency range of $295 \mathrm{~cm}^{-1}$ and about $350 \mathrm{~cm}^{-1}$. Meanwhile, above $350 \mathrm{~cm}^{-1}$, there also demonstrates another "forbidden gap" located within the regime of about $353 \mathrm{~cm}^{-1}$ and about $376 \mathrm{~cm}^{-1}$.

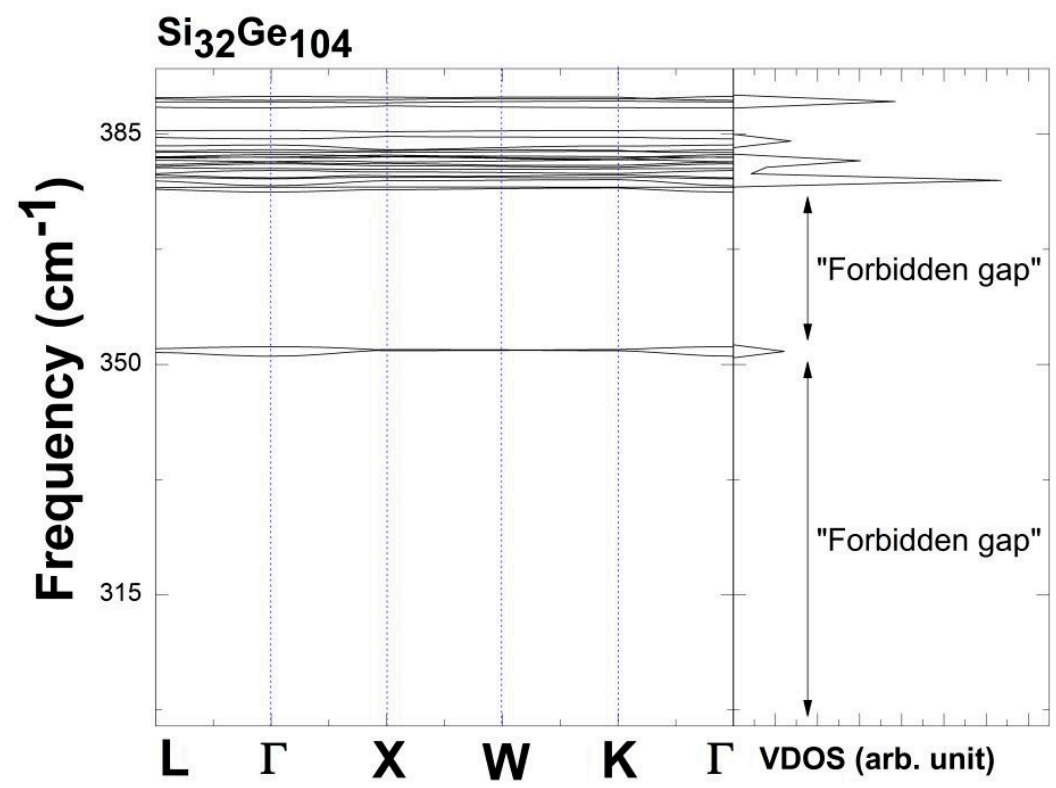

Figure 8. Plot of "forbidden gap" along with the thin peak around $350 \mathrm{~cm}^{-1}$ for $\mathrm{Si}_{32} \mathrm{Ge}_{104}$, in terms of dispersion relation and vibrational density of states.

According to the DFT-determined diagram (Figure 9), we see how the number of Ge-Ge bonds that are formed relates to the Si-fraction-dependent mode Grüneisen parameter of TA (1) and LA phonons at various high-symmetry points in $\left[\mathrm{Si}_{\mathrm{x}^{\prime \prime}} \mathrm{Ge}_{1-\mathrm{x}^{\prime \prime}}\right]_{136}\left(0<x^{\prime \prime}<1\right)$. Here, $\gamma_{\mathrm{i}}$ is computed theoretically via $\gamma_{\mathrm{i}}=\left(-V / \omega_{\mathrm{i}}\right)\left(\Delta \omega_{\mathrm{i}} / \Delta V\right)$ using the finite different method. Despite the almost constant calculated value of $\gamma_{\mathrm{i}}$ of an LA phonon that is located near the gamma point, the remaining mode Grüneisen parameters of the same phonon confined to the BZ boundary ( $\mathrm{L}$ and $\mathrm{X}$ points) are positive in sign and exhibit approximately decreasing trends as the number of $\mathrm{Ge}-\mathrm{Ge}$ bonds decreases from 36 to 8. In addition, the negative value of $\gamma_{\mathrm{i}}$ for an acoustic phonon at the zone center or boundary also approximately decreases with increasing $\mathrm{Si}$ fraction. The determined ratio of $\gamma_{\mathrm{TA}(1)}(L)$ representing $\gamma_{\mathrm{i}}$ of a TA (1) phonon at L-point for $\mathrm{Si}_{32} \mathrm{Ge}_{104}$ to $\gamma_{\mathrm{TA}(1)}(L)$ for $\mathrm{Si}_{104} \mathrm{Ge}_{32}$ is approximately 0.72; hence, the lattice framework exhibits a weak vibrational response upon geometry dilation when the $\mathrm{Ge}$ fraction dominates. 


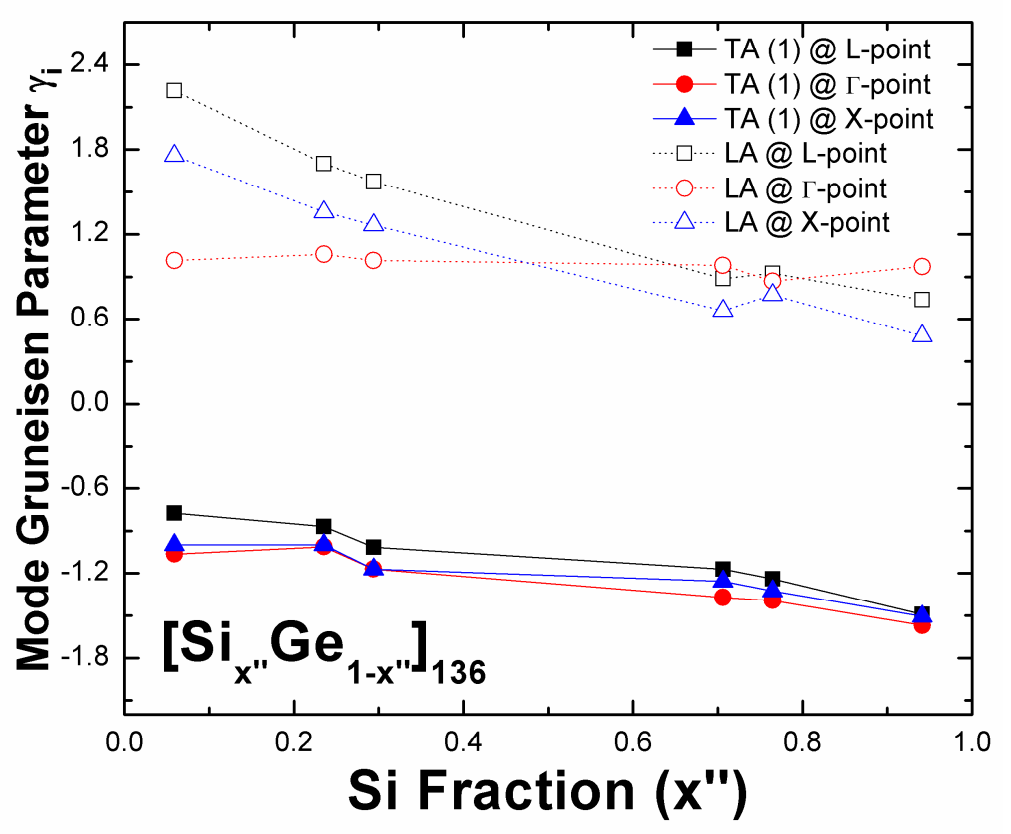

Figure 9. Predicted mode Grüneisen parameters for TA (1) and LA phonons that are confined at the Brillouin zone boundary and center, as functions of the $\mathrm{Si}$ content $x^{\prime \prime}$ in $\left[\mathrm{Si}_{\mathrm{x}^{\prime \prime}} \mathrm{Ge}_{1-\mathrm{x}^{\prime \prime}}\right]_{136}$.

The results of the following first-principles calculations (Figure 10) demonstrate the low-energy $\left(0-125 \mathrm{~cm}^{-1}\right)$ band structures of the phonon dispersions along the L- $\Gamma-\mathrm{X}$ line for $\mathrm{Si}_{128} \mathrm{Ge}_{8}$ and $\mathrm{Si}_{8} \mathrm{Ge}_{128}$, respectively. To illustrate the dilation geometry effect on the lattice framework anharmonicity, for our plotted phonon spectrum (dashed line), we consider expanded unit cell that is $+6 \%$ larger than the material's optimized structure (see "opt. system" in Figure 10a) in $\mathrm{Si}_{128} \mathrm{Ge}_{8}$ to facilitate comparison. Similarly, in $\mathrm{Si}_{8} \mathrm{Ge}_{128}$, the expanded unit cell remains $6 \%$ larger than the material's "opt. system" in Figure 10b. We allow the expanded volume for each material to be $+6 \%$ times larger than their optimized geometry. This is due to the reason that, the extremely low resolution corresponding to the variation on the wave-vector-dependent phonon mode in the low-frequency $\omega_{\mathrm{i}}(\boldsymbol{q})$ regime (such as $0-100 \mathrm{~cm}^{-1}$ ) causes the dispersion relation spectrum difficult to identify, if we use the fractional change in volume that is less than $+4 \%$. The red shift of the peak of the vibrational density of states (VDOS) at approximately $68 \mathrm{~cm}^{-1}$ in the "opt. system" of $\mathrm{Si}_{8} \mathrm{Ge}_{128}$ is attributable to suppression of its lowest-optic phonon modes (TO branches). A similar red shift of VDOS in optimized $\mathrm{Si}_{128} \mathrm{Ge}_{8}$ is observed for optic phonons, which is in the range of $100 \mathrm{~cm}^{-1}$ and $110 \mathrm{~cm}^{-1}$. 

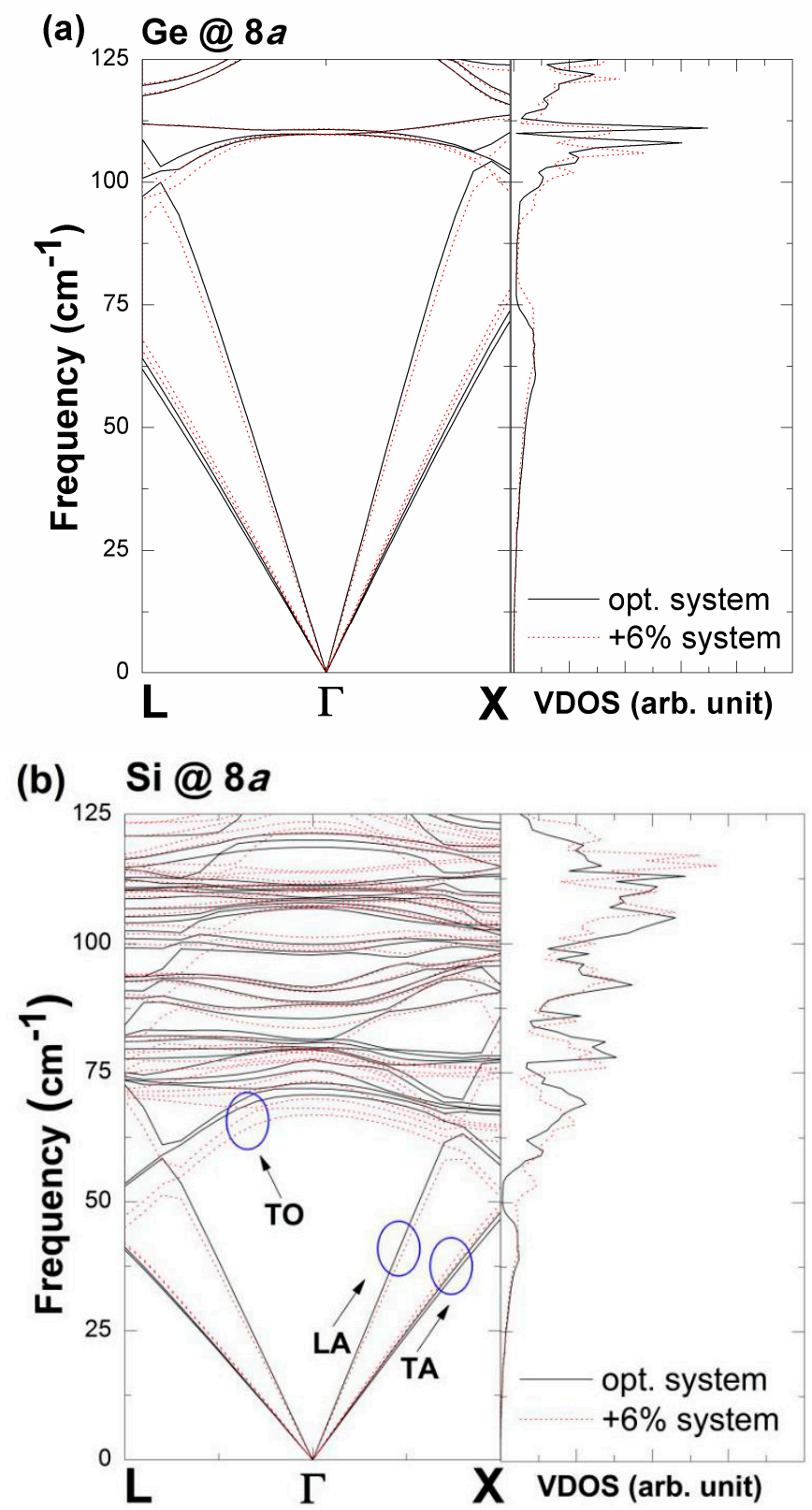

Figure 10. Low-frequency dispersion relation curves of (a) $\mathrm{Si}_{128} \mathrm{Ge}_{8}\left(\mathrm{Ge} @ 8 a\right.$ ) and (b) $\mathrm{Si}_{8} \mathrm{Ge}_{128}(\mathrm{Si} @ 8 a)$ along the L- $\Gamma-\mathrm{X}$ line, which correspond to the original geometry (solid line) and the dilated configuration (dotted line). LDA-calculated results on the vibrational density of states are also shown. The circled areas correspond to the longitudinal acoustic phonon branch and the transverse acoustic phonon branches along with transverse optical phonon branches with double degeneracy.

Thus, the apparent reduction of the mode frequency values for the degenerate TO band in the "+6\% system" (Figure 10b), in which the wave-vector spans over the Brillouin zone, results in the existence of positive mode Grüneisen parameters. On the other hand, the phonon frequency for TA branch is elevated in both materials for enlarged geometry, relative to its counterpart ("opt. system" in $\mathrm{Si}_{128} \mathrm{Ge}_{8}$ and "opt. system" in $\left.\mathrm{Si}_{8} \mathrm{Ge}_{128}\right)$. Hence, the value of $\gamma_{\mathrm{i}}(\boldsymbol{q})$ is negative, which is anticipated to contribute efficiently and dominantly to inducing the low-temperature negative thermal expansion (NTE) phenomenon to occur.

The exact mode Grüneisen parameters of the specified phonon that are obtained via LDA are listed in Table 2. The measured or theoretically estimated values are obtained at high-symmetry points $\Gamma$ and 
$\mathrm{L}$ of BZ in the direction given by [111]. It is noted that Wei et al. has reported some predictions [46] on $\gamma_{\mathrm{i}}$ of $d$-Si before. All transverse acoustic phonons considered here have $\gamma_{\mathrm{i}}$ values that are below zero. The calculated values of $\gamma_{\mathrm{i}}$ at the $\mathrm{L}$ point for $\mathrm{Si}_{128} \mathrm{Ge}_{8}$ are similar to the experimentally determined values of $\gamma_{\mathrm{i}}$ for diamond-phase silicon (see Ref. [35]). The mode Grüneisen parameter of the LA phonon at the $\Gamma$ point lies between 0.90 and 1.03 for a series of $\mathrm{Si}_{136-\mathrm{x}} \mathrm{Ge}_{\mathrm{x}}$, thereby resulting in fair comparison with the value of 1.18 that was determined for $\mathrm{Na}_{1} \mathrm{Si}_{136}$ via Raman-scattering experiments. These calculated results also correlate to the $\gamma_{\mathrm{i}}$ value of 1.1 that was obtained experimentally for diamond-phase silicon.

Table 2. Comparison of mode Grüneisen parameters between experimentally studied $\mathrm{Na}_{1} \mathrm{Si}_{136}$ [35] clathrate along with diamond-phase silicon [35] and theoretically explored $\mathrm{Si}_{136-\mathrm{x}} \mathrm{Ge}_{\mathrm{x}}(8 \leq x \leq 128)$, along the $\Gamma$-L line ([111]) direction.

\begin{tabular}{|c|c|c|c|}
\hline Material & Mode & $\mathbf{L}$ & $\Gamma$ \\
\hline \multirow[t]{2}{*}{$\mathrm{Si}_{8} \mathrm{Ge}_{128}$} & TA (1) & -0.76 & -1.04 \\
\hline & LA & 2.18 & 0.98 \\
\hline \multirow{2}{*}{$\mathrm{Si}_{32} \mathrm{Ge}_{104}$} & TA (1) & -0.85 & -1.01 \\
\hline & LA & 1.68 & 1.03 \\
\hline \multirow[t]{2}{*}{$\mathrm{Si}_{96} \mathrm{Ge}_{40}$} & TA (1) & -1.16 & 1.32 \\
\hline & LA & 0.87 & 0.96 \\
\hline \multirow{2}{*}{$\mathrm{Si}_{104} \mathrm{Ge}_{32}$} & TA (1) & -1.20 & -1.35 \\
\hline & LA & 0.90 & 0.90 \\
\hline \multirow[t]{2}{*}{$\mathrm{Si}_{128} \mathrm{Ge}_{8}$} & TA (1) & -1.43 & -1.51 \\
\hline & LA & 0.71 & 0.93 \\
\hline \multirow[t]{2}{*}{$d$-Si (Exp.) } & TA (1) & -1.30 & 0.05 \\
\hline & LA & 0.90 & 1.10 \\
\hline $\mathrm{Na}_{1} \mathrm{Si}_{136}$ & TA (1) & - & 1.18 \\
\hline
\end{tabular}

In addition to anharmonicity exploration on the low-lying acoustic modes of phonons, our computations demonstrate that the $\gamma_{\mathrm{i}}$ values for most of the optical phonon modes are positive. Guided by the quasi-harmonic approximation method, our theoretically derived macroscopic Grüneisen parameter, namely, $\gamma(T)$, is the weighted average of mode Grüneisen parameter $\gamma_{\mathbf{i}}$, which is expressed as $\gamma(T)=\sum_{\mathrm{i}} \gamma_{\mathrm{i}} C_{\mathrm{V}, \mathrm{i}} / \sum_{\mathrm{i}} C_{\mathrm{V}, \mathrm{i}}[47,48]$ where $C_{\mathrm{V}, \mathrm{i}}$ is the partial vibrational mode contribution to the heat capacity. In other words, $\gamma(T)$ is related to the anharmonicity of the lattice vibrations and describes how the vibrational frequencies (phonons) change as the volume is varied through $\gamma_{\mathrm{i}}$.

In addition, $\gamma(T)$ also serves as an indirect tool for surveying anomalous thermal expansion because $\gamma(T)=\alpha_{\mathrm{V}}(T) K_{\mathrm{T}} / C_{\mathrm{V}} \rho[49,50]$ where $\alpha_{\mathrm{v}}(T)$ denotes the volumetric thermal expansion coefficient. The sign of $\alpha_{\mathrm{v}}(T)$ depends directly on whether $\gamma(T)$ is negative or positive since the bulk modulus at the specified temperature $K_{\mathrm{T}}$ and heat capacity $C_{\mathrm{V}}$, along with material's density $\rho$, always remains positive. The results of our first-principles calculation of the overall Grüneisen parameter for $\mathrm{Si}_{136-\mathrm{x}} \mathrm{Ge}_{\mathrm{x}}$ $(x=32,40,96$, and 104) is shown in Figure 11, where the axis of abscissa gives rise to a temperature that is limited from $3 \mathrm{~K}$ to $99 \mathrm{~K}$. The values of the Grüneisen parameter $\gamma(T)$ for $\mathrm{Si}_{104} \mathrm{Ge}_{32}$ and $\mathrm{Si}_{96} \mathrm{Ge}_{40}$ have similar temperature profiles and are always negative from $3 \mathrm{~K}$ to approximately $80 \mathrm{~K}$ under the scenario of null formation of Ge-Ge bonding. These results on predicting NTE effect can be compared to the reported work of Tang et al., who experimentally and theoretically investigated the thermal properties of $\mathrm{Si}_{136}$ and pointed out an NTE region exists between in the 10-140 K temperature range [24]. However, increased numbers of $\mathrm{Ge}-\mathrm{Ge}$ bonds in $\mathrm{Si}_{40} \mathrm{Ge}_{96}$ and $\mathrm{Si}_{32} \mathrm{Ge}_{104}$ may weaken the NTE effect substantially: the predicted Grüneisen parameters for $\mathrm{Si}_{40} \mathrm{Ge}_{96}$ and $\mathrm{Si}_{32} \mathrm{Ge}_{104}$ remain negative from $3 \mathrm{~K}$ to the reduced upper temperature limit, which is approximately $20 \mathrm{~K}$. Further exploration of how the bonding geometry of the Ge-Ge covalent bond (including the bond angle and bond-bond length) impacts the NTE behavior in $\mathrm{Si}_{136-\mathrm{x}} \mathrm{Ge}_{\mathrm{x}}$ is beyond the scope of this study. 


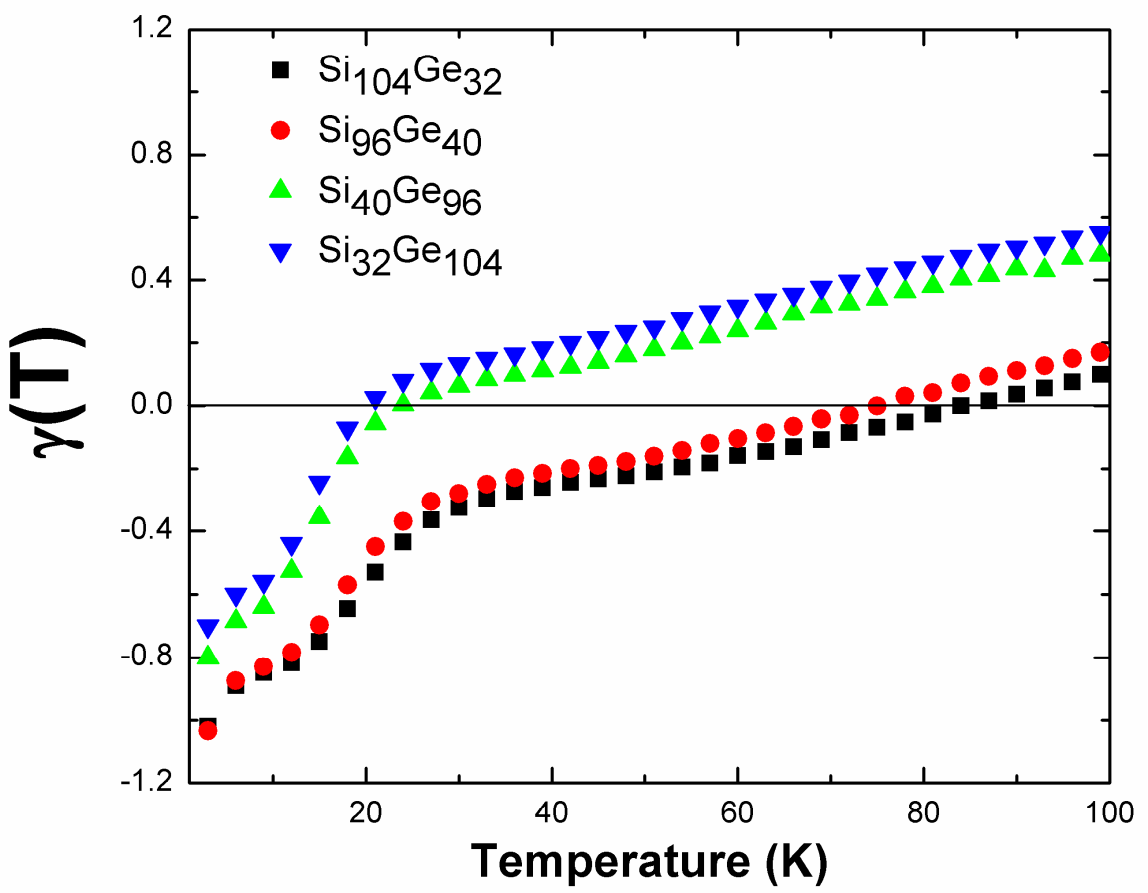

Figure 11. Density functional theory (DFT)-predicted macroscopic Grüneisen parameters of $\mathrm{Si}_{104} \mathrm{Ge}_{32}$, $\mathrm{Si}_{96} \mathrm{Ge}_{40}, \mathrm{Si}_{40} \mathrm{Ge}_{96}$ and $\mathrm{Si}_{32} \mathrm{Ge}_{104}$.

We decouple the effect of the lowest-lying phonon branches, which contribute to the production of negative mode-dependent Grüneisen parameters, from the contribution of all other phonon modes along all possible high-symmetry directions (see Figure 12a,b). The two lowest phonon bands (transverse acoustic branches), rather than the remaining 100 branches, which are confined to a unit cell of the clathrate system, are anticipated to play a substantial role in producing the NTE phenomenon. Hence, the macroscopic $\gamma(T)$ can be calculated primarily from the TA mode contribution via $\gamma_{\mathrm{TA}}(T)$ $=\gamma(T)-\gamma_{\left\langle\omega^{\prime}\right\rangle}(T)$, where $\gamma_{\left\langle\omega^{\prime}\right\rangle}(T)$, which is relatively small, describes the weighted average of the overall Grüneisen parameter over all optical branches, plus the LA phonon mode contribution. In Figure $12, \gamma_{\mathrm{TA}}(T)$ dominates $\gamma(T)$. It is noted that, the sign of the difference between parameter $\gamma_{\mathrm{TA}}(T)$ and $\gamma(T)$ can indicate within what temperature regime, the transverse acoustic phonons may play a much greater role in contributing to the induction of negative thermal expansion behavior than other phonons. As shown in the Figure 12, when the temperature is increasing towards about $80 \mathrm{~K}$ in $\mathrm{Si}_{104} \mathrm{Ge}_{32}$ (or $20 \mathrm{~K}$ in $\mathrm{Si}_{32} \mathrm{Ge}_{104}$ ), the temperature-dependent macroscopic Grüneisen parameter approaches almost zero, leading to the vanishing behavior of NTE. Thus, existence of the positive difference $\left(\gamma(T)-\gamma_{\mathrm{TA}}(T)>0\right)$ in Figure 12 indicates that, vibration of TA phonons occurring in the temperature range of 0 and $30 \mathrm{~K}$ in $\mathrm{Si}_{104} \mathrm{Ge}_{32}$ (or in the range of 0 and $20 \mathrm{~K}$ in $\mathrm{Si}_{32} \mathrm{Ge}_{104}$ ) can contribute more effectively to the induction of NTE than the rest of phonons. 



Figure 12. Predicted weighted Grüneisen parameters for transverse acoustic phonons $\left(\gamma_{\mathrm{TA}}(T)\right)$ and the contribution of all phonon modes $(\gamma(T))$ as functions of temperature for (a) $\mathrm{Si}_{104} \mathrm{Ge}_{32}$ and (b) $\mathrm{Si}_{32} \mathrm{Ge}_{104}$.

\section{Conclusions}

We have employed the ab initio DFT method to conduct systematic investigations on the electronic, vibrational and thermodynamic properties of the $\mathrm{Si}_{136-\mathrm{x}} \mathrm{Ge}_{\mathrm{x}}$ clathrates. Most of the DFT results relate to vibrational features. We found that low-frequency transverse acoustic phonons, which have an unusual anharmonic vibration response (negative $\gamma_{\mathrm{i}}$ ) to slight structural expansion, are primarily responsible for the occurrence of the NTE phenomenon. In addition, the reduction of the maximum optic band spectrum and the suppression of the acoustic phonon band width are accompanied by an increase in the number of Ge-Ge bonds that are formed, from 0 (or 8) to 36. Moreover, the number of Ge-Ge bonds is expected to affect the upper limit of the temperature range beyond which NTE vanishes, thereby making it possible to have a strongly weakened NTE effect when $x$ changes from 32 (or 40 ) to 96 (or 104) in $\mathrm{Si}_{136-\mathrm{x}} \mathrm{Ge}_{\mathrm{x}}$. Our structural investigation of $\mathrm{Si}_{136-\mathrm{x}} \mathrm{Ge}_{\mathrm{x}}(0 \leq x \leq 128)$ serves as the 
fundamental step for initiating our entire first-principles work, since all vibrational and thermodynamic properties are extracted, in addition to the optimized geometry of each alloy. Our LDA-determined lattice parameter agrees well with XRD data: both show almost monotonically increasing behavior as the Ge composition, namely, $x$, increases. Regarding the electronic properties, the previous DFT results, which were obtained using the CASTEP code, reveal an optical band gap of $\mathrm{Si}_{128} \mathrm{Ge}_{8}$ of $1.23 \mathrm{eV}$, which agrees extremely well with the result of our calculation via VASP $(\sim 1.27 \mathrm{eV})$. The tunable band gap modulated by Ge content in $\mathrm{Si}_{136-\mathrm{x}} \mathrm{Ge}_{\mathrm{x}}$ has attracted attention for photovoltaic (PV) applications, because alloyed SiGe semiconductors demonstrating "nearly-direct" or direct wide band gap may be a very suitable and practical choice for optoelectronics applications $[27,37]$ due to their reduced weight and cost.

Author Contributions: Conceptualization, D.X.; methodology, D.X.; software, C.W.M.; validation, D.X., C.W.M.; formal analysis, D.X.; investigation, D.X.; resources, C.W.M.; data curation, D.X.; writing-original draft preparation, D.X.; writing—review and editing, D.X.; visualization, D.X.; supervision, C.W.M.; project administration, C.W.M.

Funding: This research received no external funding.

Acknowledgments: We would like to acknowledge grateful discussions with Mahdi Sanati (Texas Tech University) about the use of VASP. We also appreciate many hours of computing time at the High Performance Computing Center of Texas Tech University.

Conflicts of Interest: The authors declare no conflict of interest.

\section{References}

1. Biswas, K.; Myles, C.W. Electronic structure of the $\mathrm{Na}_{16} \mathrm{Rb}_{8} \mathrm{Si}_{136}$ and $\mathrm{K}_{16} \mathrm{Rb}_{8} \mathrm{Si}_{136}$ clathrates. Phys. Rev. B 2006, 74, 115113. [CrossRef]

2. Kawaji, H.; Horie, H.; Yamanaka, S.; Ishikawa, M. Superconductivity in the Silicon Clathrate Compound $(\mathrm{Na}, \mathrm{Ba})_{\mathrm{x}} \mathrm{Si}_{46}$. Phys. Rev. Lett. 1995, 74, 1427. [CrossRef] [PubMed]

3. Yamanaka, S.; Horie, H.; Kawaji, H.; Ishikawa, M. Preparation and Superconductivity of Barium Containing Silicon Clathrate Compound, (Ba, $\mathrm{K}_{\mathrm{x}} \mathrm{Si}_{46}$. ChemInform 1996, 27. [CrossRef]

4. Kawaji, H.; Iwai, K.; Yamanaka, S.; Ishikawa, M. Composition dependence of the superconducting transition temperature of silicon clathrate compound $\mathrm{Na}_{x} \mathrm{Ba}_{6} \mathrm{Si}_{46}$. Solid State Commun. 1996, 100, 393. [CrossRef]

5. Yamanaka, S.; Enishi, E.; Fukuoka, H.; Yasukawa, M. High-Pressure Synthesis of a New Silicon Clathrate Superconductor, $\mathrm{Ba}_{8} \mathrm{Si}_{46}$. Inorg. Chem. 2000, 39, 56. [PubMed]

6. Suekuni, K.; Avila, M.A.; Umeo, K.; Takabatake, T. Cage-size control of guest vibration and thermal conductivity in $\mathrm{Sr}_{8} \mathrm{Ga}_{16} \mathrm{Si}_{30-x} \mathrm{Ge}_{\mathrm{x}}$. Phys. Rev. B 2007, 75, 195210. [CrossRef]

7. Nakagawa, N.; Miyake, M.; Hayase, H.; Koyanagi, T. Thermoelectric Conversion Symposium Proceeding; Tokyo, Japan, 2002; pp. 136-137.

8. Martin, J.; Erickson, S.; Nolas, G.S.; Alboni, P.; Tritt, T.M.; Yang, J. Structural and transport properties of $\mathrm{Ba}_{8} \mathrm{Ga}_{16} \mathrm{Si}_{\mathrm{x}} \mathrm{Ge}_{30-\mathrm{x}}$ clathrates. J. Appl. Phys. 2006, 99, 044903. [CrossRef]

9. Chen, G. Thermal conductivity and ballistic-phonon transport in the cross-plane direction of superlattices. Phys. Rev. B 1998, 57, 14958. [CrossRef]

10. Ioffe, A.F. Thermoelements and Thermoelectric Cooling; Infosearch Limited: London, UK, 1957.

11. Myles, C.W.; Dong, J.; Sankey, O.F. Rattling Guest Atoms in Si, Ge and Sn-based Type II Clathrate Materials. Phys. Status Solidi B 2003, 239, 26.

12. Mano, S.; Onimaru, T.; Yamanaka, S.; Takabatake, T. Off-center rattling and thermoelectric properties of type-II clathrate $(\mathrm{K}, \mathrm{Ba})_{24}(\mathrm{Ga}, \mathrm{Sn}, \square)_{136}$ single crystals. Phys. Rev. B 2011, 84, 214101. [CrossRef]

13. Nolas, G.S.; Kendziora, C.A.; Gryko, J.; Dong, J.; Myles, C.W.; Poddar, A.; Sankey, O.F. Raman scattering study of stoichiometric Si and Ge type II clathrates. J. Appl. Phys. 2002, 92, 7225. [CrossRef]

14. Nolas, G.S.; Vanderveer, D.G.; Wilkinson, A.P.; Cohn, J.L. Temperature dependent structural and transport properties of the type II clathrate $\mathrm{A}_{8} \mathrm{Na}_{16} \mathrm{E}_{136}(\mathrm{~A}=\mathrm{Cs}$ or $\mathrm{Rb}$ and $\mathrm{E}=\mathrm{Ge}$ or Si). J. Appl. Phys. 2002, 91, 8970. [CrossRef]

15. Tse, J.S.; Uehara, K.; Rousseau, R.; Ker, A.; Ratcliffe, C.I.; White, M.A.; Mackay, G. Structural principles and amorphuslike thermal conductivity of Na-doped Si clathrates. Phys. Rev. Lett. 2001, 86, 4980. [CrossRef] 
16. Beekman, M.; Wong-Ng, W.; Kaduk, J.A.; Shapiro, A.; Nolas, G.S. Synthesis and single-crystal X-ray diffraction studies of new framework substituted type II clathrates, $\mathrm{Cs}_{8} \mathrm{Na}_{16} \mathrm{Ag}_{\mathrm{x}} \mathrm{Ge}_{136-\mathrm{x}}(\mathrm{x}<7)$. J. Solid State Chem. 2007, 180, 1076. [CrossRef]

17. Gryko, J.; Marzke, R.F.; Lamberton, G.A.; Tritt, T.M.; Beekman, M.; Nolas, G.S. Electron structure and temperature-dependent shifts in ${ }^{133}$ Cs NMR spectra of the $\mathrm{Cs}_{8} \mathrm{Ge}_{136}$ clathrate. Phys. Rev. B. 2005, 71, 115208. [CrossRef]

18. Nolas, G.S.; Slack, G.A.; Morelli, D.T.; Tritt, T.M.; Ehrlich, A.C. The effect of rare-earth filling on the lattice thermal conductivity of skutterudites. J. Appl. Phys. 1996, 79, 4002. [CrossRef]

19. Nolas, G.S.; Kendziore, C.A. Raman scattering study of Ge and Sn compounds with type-I clathrate hydrate crystal structure. Phys. Rev. B 2000, 62, 7157. [CrossRef]

20. Slack, G.A. CRC Handbook of Thermoelectrics; Rowe, D.M., Ed.; CRC: Boca Raton, FL, USA, 1995; pp. $407-440$.

21. Slack, G.A. Proceedings of Thermoelectric Materials: New Directions and Approaches; MRS Symposia Proceedings No. 478; Materials Research Society: Pittsburgh, PA, USA, 1997; p. 47.

22. Biswas, K.; Myles, C.W. Electronic and vibrational properties of framework-substituted type-II silicon clathrates. Phys. Rev. B 2007, 75, 245205. [CrossRef]

23. Nenghabi, E.N.; Myles, C.W. First-principles calculations of the vibrational and thermal properties of the type-I clathrates $\mathrm{Ba}_{8} \mathrm{Ga}_{16} \mathrm{Si}_{x} \mathrm{Ge}_{30-x}$ and $\mathrm{Sr}_{8} \mathrm{Ga}_{16} \mathrm{Si}_{x} \mathrm{Ge}_{30-x}$. Phys. Rev. B 2008, 78, 195202. [CrossRef]

24. Tang, X.; Dong, J.; Hutchins, P.; Shebanova, O.; Gryko, J.; Barnes, P.; Cockcroft, J.K.; Vickers, M.; McMillan, P.F. Thermal properties of $\mathrm{Si}_{136}$ : Theoretical and experimental study of the type-II clathrate polymorph of $\mathrm{Si}$. Phys. Rev. B 2006, 74, 014109. [CrossRef]

25. Nolas, G.S.; Beekman, M.; Gryko, J.; Lamberton, G.A., Jr.; Tritt, T.M.; McMillan, P.F. Thermal conductivity of elemental crystalline silicon clathrate $\mathrm{Si}_{136}$. App. Phys. Lett. 2003, 82, 910. [CrossRef]

26. Beekman, M.; Kaduk, J.A.; Wong-Ng, W.; Troesch, M.; Lee, G.S.; Nolas, G.S. Control of thermal expansion in a low-density framework modification of silicon. App. Phys. Lett. 2018, 112, 181901. [CrossRef]

27. Martinez, A.D.; Krishna, L.; Baranowski, L.L.; Lusk, M.T.; Toberer, E.S.; Tamboli, A.C. Synthesis of Group IV clathrates for photovoltaics. IEEE J. Photovolt. 2013, 4, 1305. [CrossRef]

28. Zhao, J.; Buldum, A.; Lu, J.; Fong, C.Y. Structural and electronic properties of germanium clathrates $\mathrm{Ge}_{46}$ and $\mathrm{K}_{8}$ Ge46. Phys. Rev. B 1999, 60, 14177. [CrossRef]

29. Nolas, G.S.; Cohn, J.L.; Slack, G.A.; Schujman, S.B. Semiconducting Ge clathrates: Promising candidates for thermoelectric applications. Appl. Phys. Lett. 1998, 73, 178. [CrossRef]

30. Herrmann, R.F.W.; Tanigaki, K.; Kawaguchi, T.; Kuroshima, S.; Zhou, O. Electric structure of Si and Ge gold-doped clathrates. Phys. Rev. B 1999, 60, 13245. [CrossRef]

31. Moriguchi, K.; Munetoh, S.; Shintani, A. First-principles study of $\mathrm{Si}_{34-\mathrm{x}} \mathrm{Ge}_{\mathrm{x}}$ clathrates: Direct wide-gap semiconductors in Si-Ge alloys. Phys. Rev. B 2000, 62, 7138. [CrossRef]

32. Harkonen, V.J.; Karttunen, A.J. Ab initio lattice dynamical studies of silicon clathrate frameworks and their negative thermal expansion. Phys. Rev. B 2014, 89, 024305. [CrossRef]

33. Harkonen, V.J.; Karttunen, A.J. Ab initio studies on the lattice thermal conductivity of silicon clathrate framework II and VIII. Phys. Rev. B 2016, 93, 024307. [CrossRef]

34. Falenty, A.; Hansen, T.C.; Kuhs, W.F. Formation and properties of ice XVI obtained by emptying a typr sII clathrate hydrate. Nature 2014, 516, 231. [CrossRef]

35. Guyot, Y.; Grosvalet, L.; Champagnon, B.; Reny, E.; Cros, C.; Pouchard, M. Grüneisen parameters for silicon clathrates determined by Raman scattering. Phys. Rev. B 1999, 60, 14507. [CrossRef]

36. Weinstein, A.; Zallen, R. Light Scattering in Solids IV; Topics in Applied Physics; Springer: Berlin, Germany, 1984; Volume 54.

37. Baranowski, L.L.; Krishna, L.; Martinez, A.D.; Raharjo, T.; Stevanovic, V.; Tamboli, A.C.; Toberer, E.S. Synthesis and optical band gaps of alloyed Si-Ge type II clathrates. J. Mater. Chem. C 2014, 2, 3231-3237. [CrossRef]

38. Kresse, G.; Furthmuller, J. Efficient iterative schemes for ab initio total-energy calculations using a plane-wave basis set. Phys. Rev. B 1996, 54, 11169. [CrossRef]

39. Monkhorst, H.J.; Pack, J.D. Special points for Brillouin-zone integrations. Phys. Rev. B 1976, $13,5188$. [CrossRef]

40. Birch, F. Elasticity and constitution of the Earth's interior. J. Geophys. Res. 1952, 57, 227. [CrossRef] 
41. Kasper, J.S.; Hagenmuller, P.; Pouchard, M.; Cros, C. Clathrate structure of silicon $\mathrm{Na}_{8} \mathrm{Si}_{46}$ and $\mathrm{Na}_{\mathrm{x}} \mathrm{Si}_{136}$ $(\mathrm{x}<11)$. Science 1965, 150, 1713. [CrossRef]

42. Perdew, J.P.; Levy, M. Physical content of the exact Kohn-Sham orbital energies: Band gaps and derivative discontinuities. Phys. Rev. Lett. 1983, 51, 1884. [CrossRef]

43. Bechstedt, F.; Sole, R.D. Analytical treatment of band-gap underestimates in the local-density approximation. Phys. Rev. B 1988, 38, 7710. [CrossRef]

44. Dong, J.; Sankey, O.F.; Ramachandran, G.K.; McMillan, P. Chemical trends of the rattling phonon modes in alloyed germanium clathrates. J. Appl. Phys. 2000, 87, 7726. [CrossRef]

45. Biswas, K.; Myles, C.W.; Sanati, M.; Nolas, G.S. Thermal properties of guest-free $\mathrm{Si}_{136}$ and $\mathrm{Ge}_{136}$ clathrates: A first-principles study. J. Appl. Phys. 2008, 104, 033535. [CrossRef]

46. Wei, S.; Li, C.; Chou, M.Y. Ab initio calculation of thermodynamic properties of silicon. Phys. Rev. B 1994, 50, 14587. [CrossRef]

47. Roberts, R.W.; Ruppin, R. Volume dependence of the Grüneisen parameter of alkali halides. Phys. Rev. B 1971, 4, 6. [CrossRef]

48. Barron, T.H.K.; Collins, J.G.; White, G.K. Thermal expansion of solids at low temperatures. Adv. Phys. 1980, $29,609$. [CrossRef]

49. Barron, T.H.K. Grüneisen parameters for the equation of state of solids. Ann. Phys. 1957, 1,77-90. [CrossRef]

50. Liu, Y.; Wang, Z.; Wu, M.; Sun, Q.; Chao, M.; Jia, Y. Negative thermal expansion in isostructural cubic ReO3 and ScF3: A comparative study. Comput. Mater. Sci. 2015, 107, 157-162. [CrossRef]

(C) 2019 by the authors. Licensee MDPI, Basel, Switzerland. This article is an open access article distributed under the terms and conditions of the Creative Commons Attribution (CC BY) license (http://creativecommons.org/licenses/by/4.0/). 